\title{
Access to Emergency Medical Services: An Urban Planning Methodology for the Generation of Equity
}

\author{
Juan Manuel Holguín ${ }^{1}$, Diego A. Escobar ${ }^{1} \&$ Carlos A. Moncada ${ }^{2}$ \\ ${ }^{1}$ Universidad Nacional de Colombia, Sede Manizales, Departamento de Ingeniería Civil, Colombia \\ ${ }^{2}$ Universidad Nacional de Colombia, Sede Bogotá, Departamento de Ingeniería Civil y Agrícola, Colombia \\ Correspondence: Diego A. Escobar, Carrera 27 \# 64-60, Block I, Office 408, Palogrande Campus, Manizales, \\ Caldas17004, Colombia. E-mail: daescobarga@unal.edu.co
}

\author{
Received: April 4, 2018 Accepted: May 10, 2018 Online Published: May 25, 2018 \\ doi:10.5539/gjhs.v10n6p181 \\ URL: https://doi.org/10.5539/gjhs.v10n6p181
}

\begin{abstract}
The access and possibility of rapid response to medical emergencies is an issue that, in last decades, has been studied in many areas of research such as urban planning and transportation, as well as with the issue of equity in the provision of this healthcare service. This is true, in particular for middle- and low-income countries subject to non-equitative access to services such as medical emergency attention. In this study, a medical emergency database review is carried out in order to propose a new methodology to assess the coverage of Ambulance Dispatches and Emergency Service Facilities. This is executed using primary information relating to medical emergencies that occurred in the city of Manizales between 2010 and 2015 and secondary data relating to socio-demographic and economic conditions, analyzing their correlation using a GIS (Geographic Information System) application. This research article proposes a methodology for improving the population coverage of Ambulance Dispatches and Emergency Service Facilities, trying to reduce health inequity in terms of assistance to medical emergencies. Our results show that in order to reduce social and health inequity, the city of Manizales needs to improve its provision of emergency care attention, based on urban planning tools especially in low-income neighborhoods.
\end{abstract}

Keywords: accessibility, Ambulance dispatch, emergency service facility, equity, travel time, urban planning

\section{Introduction}

The access and possibility of rapid response to medical emergencies is an issue that, in last decades, has been studied in many areas of research such as urban planning and transportation, as well as with the issue of equity in the provision of this healthcare service (Marmot, Allen, Bell, \& Goldblatt, 2012). The hypothesis of this study is that the provision of emergency services is unequal and intensified by geographical patterns of recorded emergencies, location of the Emergency Facility Services, poor urban planning and transport network operating characteristics. This research article proposes a methodology for improving the population coverage of Ambulance Dispatches (AD) and Emergency Service Facilities (ESF), seeking to reduce health inequity in terms of attention to medical emergencies. It considers concepts of geographic accessibility, attention to medical emergencies, and health equity. Furthermore, it identifies diagnoses and provides the development of these concepts by an overview of a case study. Later, this paper explains the proposed methodology to suggest the urban sectors in which AD and ESF ought to be established in order to satisfy requirements to assist a medical emergency in optimal travel time. The article concludes with a discussion on its conclusions indicating the geographical impacts of applying this technique. Exist different geographical methodologies to place the best alternative to improve access to medical emergency facilities (Cirino, L.A. Gonzalves, M.B. Gonzalves \& Souza de Cursi, 2018; Neutens, 2015), like the Enhanced Two-Step Floating Catchment Area (Bauer, Muller, Bruggmann, \& Groneberg, 2017; Langford, Higgs, \& Fry, 2016), for example, which according to Nakamura et al (2017) is superior for analyzing spatial access to hospital, . The World Health Organization (WHO) reports that the primary causes of death in the world are ischemic heart disease, followed by cerebrovascular disease, and infections: respiratory, gastrointestinal, HIV (Human Immunodeficiency Virus) and tuberculosis. Cancer and traffic accidents are placed in the eighth and ninth positions respectively (Mathers \& Loncar, 2006). These distributions vary between high- and low-income countries. Every patient deserves timely quality attention. However, in critical patients, time is of particular value. It is related with the health outcomes, and most importantly with long-term morbidity and mortality indexes. The causes of death in people that suffer injury are: respiratory problems and failure or uncontrolled hemorrhage, 
which can be controlled with first-aid (Varghese, Sasser, Kellermann, \& Lormand, 2005). The 2010 American Heart Association (AHA) Guidelines for Cardio Pulmonary Resuscitation (CPR) and Emergency Cardiac Care (ECC) for the evaluation and management of Acute Coronary Syndromes (ACS), mention that half of the patients with ACS do not survive the transport time (O'Connor et al., 2010). Treatment prognosis depends on its early implementation, and its main goals are to prevent the extension of myocardial necrosis and to minimize the consequences, especially those responsible for cardiac arrest. In some studies, the early administration of aspirin has been proven to have a significant impact on decreasing mortality (Freimark et al., 2002). The treatment of cerebrovascular disease or stroke has three principal goals: to limit the number of ischemic events, improve blood supply, and begin the secondary measures for functional recovery, all of which depend on the rapid instauration of the diagnosis (Jauch et al., 2011). Intravenous thrombolysis is the treatment of choice for acute ischemic stroke, with optimal response if administered in the first 1.5 hours after the onset of the symptoms, and a modest response after 3 to 4.5 hours with a higher risk of hemorrhage (Hacke et al., 2008). The lenght of time from the event and sixty minutes after injury occurs is called 'The golden hour' in the pre-hospital trauma care terms (Carr, Caplan, Pryor, \& Branas, 2006). A McCoy et al. study (2013) found a relation between transport time and scene time in trauma patients demises. When arrival to the scene takes longer than 20 minutes, the odds for mortality were higher in comparison with less than 10 minutes arrival to the scene time (McCoy, Menchine, Sampson, Anderson, \& Kahn, 2013). Another study by Neutens (2015) found that if the response time decreases by 10 minutes the mortality indexes in road crashes reduce by around $30 \%$. People presenting cardiac arrest have very low probabilities of survival with a mortality index of close to $95 \%$. Those who receive prompt response are much more likely to survive than those who do not, as early cardiopulmonary resuscitation and defibrillation is required to avoid fatality (Sasson, Rogers, Dahl, \& Kellermann, 2010). Different studies have shown the importance of response time. A randomized trial concludes that the outcome from ventricular fibrillation is better with response times of 3 minutes than response times longer than 7 minutes (Cone, 2004). The AHA Guidelines for CPR and ECC exposed the importance of CPR in the prevention of the long-term disabilities, highlighting that if CPR is performed immediately, the patient could survive with intact neurological function. This is even more likely if defibrillation is performed within 5 to 10 minutes (Field et al., 2010).

Another study of patients with acute chest pain, showed a significant delay in response time depending on the types of insurance coverage: patients with 'Medicaid' (non-private insurance in United States) are more significantly affected than patients with private insurance. Differences in response time associated with race, sex and cardiac disease history were not statistically significant (Brown, Schneider, Colbert, \& Guss, 1998). A study by Foraker et al. (2008) demonstrated a correlation between services attended in low-income neighborhoods and delais in prehospital care, concluding that inequity influences response time. Every health system in the world tries to improve health with minimum variance in attention between ethnic or social groups, respecting human dignity and rights, and seeking equity in terms of service and access to facilities (Braveman \& Gruskin, 2003; Shaikh \& Ali, 2016). For instance, life expectancy rose by 30 years for Europeans in the last century. While, life expectancy in Asians between 1970 and 2000 increased by only 13 years, and in sub-Saharan Africa, it rose by 4 months in the same period (United Nations Development Programmed [UNDP], 2005). Even in Latin America and poorer countries, some studies have found a positive impact of the gross domestic product on public health, such as infant mortality rates, tuberculosis mortality rates and life expectancy when inequality decreases due to a better distribution of wealth (Dollar \& Kraay, 2002; Biggs, King, Basu, \& Stuckler, 2010). For example, a study detected severe complications in patients referred by health workers for high-level care, among which maternal deaths in Zimbabwe were found (Fawcus, Mbizvo, Lindmark, \& Nyström, 1997). In addition, in low-and middle-income countries, a greater portion of the public budget is spent on health care services used by high-income individuals than those used by the poor (Gwatkin, Bhuiya, \& Victora, 2004).

The concept of accessibility has frequently been used in land-use planning and transport analysis during the last fifty years, although there are records of its use dating back to the 20s (Batty, 2009). Hansen defined accessibility as "The potential of opportunities for interaction" (1959). This is considered the most classical definition of this term, also establishing the first mathematical bases of the model. One planning instrument to assess the impacts of land use and transport strategies, such as the location of healthcare services is the analysis of accessibility (Geurs \& Van Wee, 2004; Higgs, 2009), which can consider different factors such as human and technological resources and access time, among others. This analysis could help to find how different urban areas can benefit -or not- from levels of accessibility, including healthcare (Higgs, 2004). Literature includes different kinds of accessibility analyses used by researchers in issues such as: social cohesion (Farrington \& Farrington, 2005), access to health systems (Escobar, Holguin, \& Zuluaga, 2016; Cheng et al., 2016; Apparicio, Gelb, Dubé, Kingham, Gauvin, \& Robitaile, 2017), change of spatial accessibility to healthcare (Yang \& Mao, 2018), equity and social exclusion in 
transport (Preston \& Raje, 2007), provision and location of library services (Calcuttawala, 2006), sustainable transport development (Cheng, Bertolini, \& le Clerq, 2007), urban development planning and land use (Geurs \& van Wee, 2004), economic development (Holl, 2007), and public transport analysis (Gulhan, Hu. Ceylan, Özuysal \& Ha. Ceylan, 2013), among many others. In relation with the accessibility issue, it is possible to find studies that seek to identify the access to medical emergency services in statistical analysis in order to detect high-risk locations of vehicle crashes, finding that any relationship between the accessibility from severe crash hotspots to hospitals with emergency services remained unclear (Ulak, Kocatepe, Ozguven, Horner, \& Spainhour, 2017).

For this study, we chose the city of Manizales in Colombia. Manizales is the capital of the Caldas Department, located at $5^{\circ} 03^{\prime} 58^{\prime \prime} \mathrm{N}$ and $75^{\circ} 29^{\prime} 05^{\prime} \mathrm{W}$ from the Greenwich meridian, in the northwest of South America, lying on the Colombian Central Mountain Range at 2,150 m.a.s.l. (see Figure 1). According to the National Administrative Institute of Statistics (DANE), it has 414,906 inhabitants in an extension of $508 \mathrm{~km} 2$ (94\% of population lives in the urban area, which measures $35.11 \mathrm{Km} 2$ ). The city has special characteristics such as abrupt topography, and a lack of adequate urban planning in its historic development on steep hills. It has been marked by limited land-use regulations that have led to the development of informal settlements that lack adecuated infrastructure, deficient basic services, and unsuitable and environmentally risky location areas (Chardon, 2008).
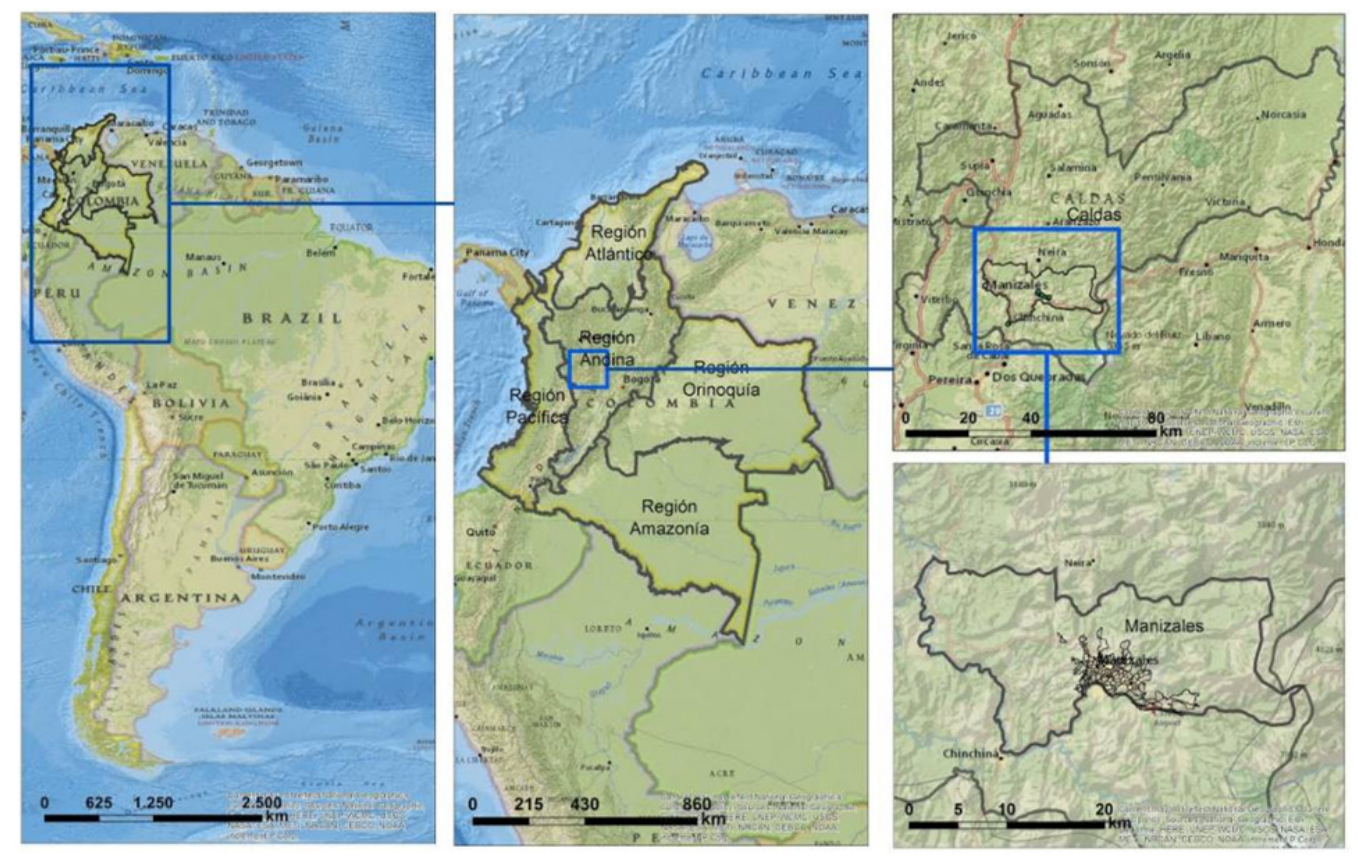

Figure 1. Location of Manizales. Source: Authors' own using ESRI data

After brief introduction, the research methodology is addressed, the main results obtained and the discussion and conclusions are presented. Finally, the references that support the proposed methodology are listed.

\section{Method}

The main target of this methodology is to identify urban areas in Manizales with deficiencies in emergency attention between $\mathrm{AD}$ and events, and between events and ESF locations, in terms of travel time. This is implemented through the development of five consecutive stages shown in Figure 2 with their description enunciated below. 


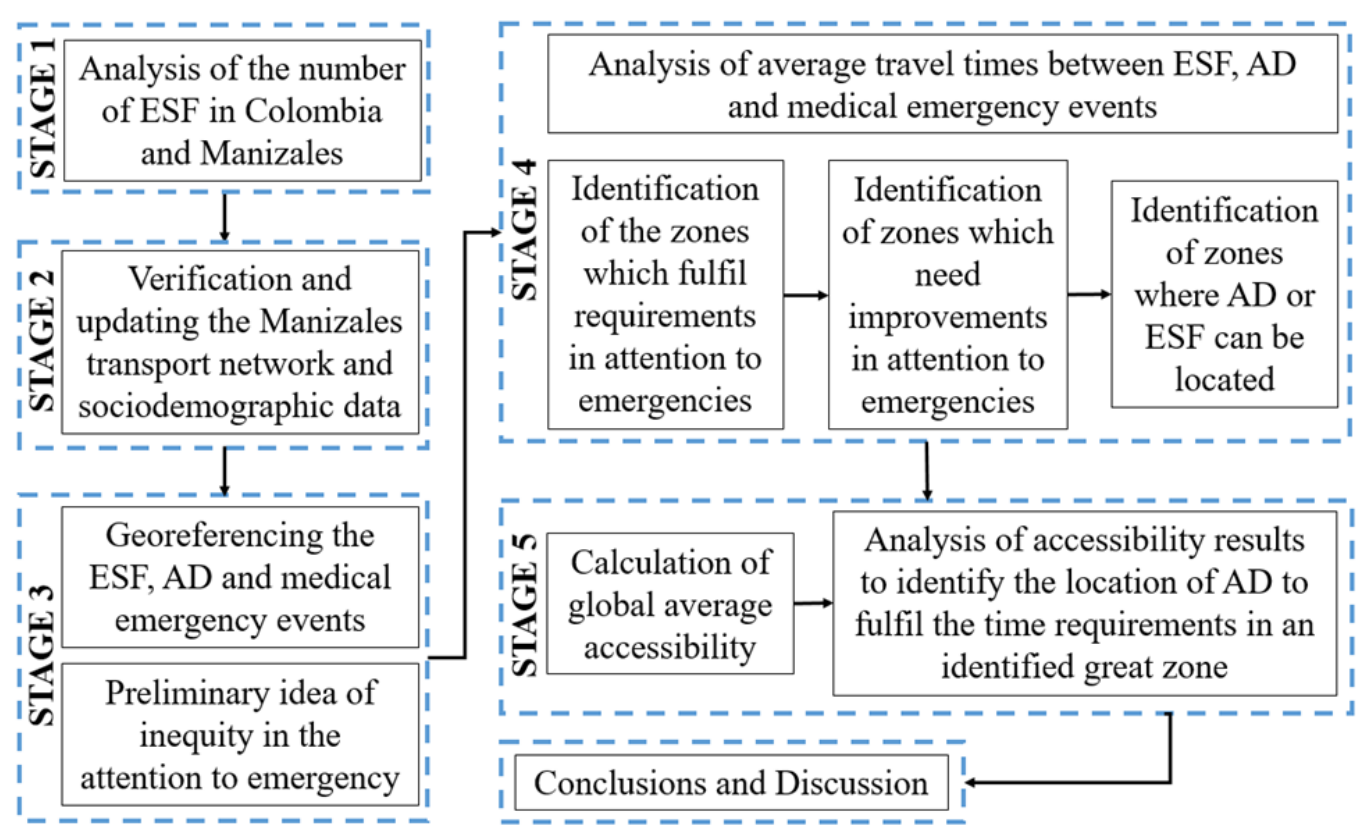

Figure 2. Research Methodology. Source: Authors' own

\subsection{Analysis of the Number of ESF in Colombia and Manizales, Stage 1}

It is known that the geographical distribution of IPS or ESF has no clear regulation in Colombia, because health services have been turned into a business whose goal is to improve profits but not necessarily to improve the health of the patients (Molina et al., 2013). In addition, Colombian Law indicates the process to create and enable a new IPS. Establishing that, these entities should fulfill a number of requirements in terms of infrastructure, management and health services, but not in terms of geospatiality or coverage. Based on secondary information, this study analyses the number of ESF that exist in Colombia and in the urban area of the Manizales municipality.

\subsection{Verification and Updating of the Manizales Transport Network and Sociodemographic Data, Stage 2}

The main planning tool to develop accessibility analysis is the transport network. This is composed of nodes and links, where nodes represent intersections and links represent road segments in which the average speed is loaded. Manizales' georeferenced transport network was created in the 2010 Master Mobility Plan (PMM), and updated based on official geographic files and documents such as the Territorial Management Plan (POT) and non-official documents including aerial photos provided by Manizales Town Hall, open street maps, street view, Google maps, among other sources. Sociodemographic data such as inhabitants, area, social stratum, network length, etc. were also loaded in the SIG.

\subsection{Georeferencing the ESF, AD and Medical Emergency Events, Stage 3}

The Colombian population is classified into six socioeconomic strata. The low-income population is located in Stratum 1 areas and the high-income population is ranked in Stratum 6 areas. Thus, based on secondary information about the location of ESF and AD, the socioeconomic strata in which the ESF and AD are located were compared to provide a preliminary idea of inequity existing with regard to medical emergency services. An analysis of the medical emergency events database provides information on: a) The zones life-threatening emergencies, b) The zones deceasesed and c)The Zones population.

\subsection{Analysis of Average Travel Times Between ESF, AD and Medical Emergency Events, Stage 4}

The most commonly used algorithm for network analyst problems is Dijkstra's multiple shortest path problem (1959). The matrix of minimum average travel time between network nodes is calculated using loaded information for the the transport network and the minimum travel time (tvi) between each node -measured using the Dkjistra algorithm- giving the average travel time (Tvi, equation 1). Following this, two important variables for the analytical research were calcualted: a) hypothetically, the minimum average travel time needed to attend a life-threatening emergency in each neighborhood as AD - event and as event - ESF (Cromley \& McLafferty, 2011);

b) Current Average travel time to attend an emergency consideraded life-threatning, from the AD and the event, 
and from the event and the ESF, taking in consideration the current operational speed transport network.

$$
\overline{T v \imath}=\frac{\sum_{j=1}^{n} t v_{i j}}{n-1} \mathrm{i}=1,2,3, \ldots, \mathrm{n} ; \quad \mathrm{j}=1,2,3, \ldots, \mathrm{n}
$$

Some research has pointed out that patients attended in a maximum of 4 minutes of response time between AD and the event have a high probability of survival (P.T. Pons, Haukoos, Bludworth, Cribley, K.A. Pons, \& Markovchick, 2005). The study showed that patients who were reached in a maximum response time of 4 minutes were subject to an average of 6 minutes of transport time. While, patients that were reached in a response time greater than 4 minutes were subject to 8.3 minutes of average transport time. In the methodological process, it is necessary to define a time limit for the analysis. First, it is necessary to find two type of zones: a) zones with a minimum average travel time and real travel time of less than 5 minutes (Blackwell \& Kaufman, 2002) between AD and emergency medical event; b) zones with a minimum average travel time of less than 6 minutes between the emergency medical event and ESF. The main target for this step is to identify the zones that fulfill the requirements of attention to emergencies. Next, it is necessary to find zones with a minimum average travel time of less than 5 minutes and 6 minutes in AD - emergency medical event, and emergency medical event - ESF trips, respectively, but a real average travel time greater than 5 minutes and 6 minutes, respectively. The main target of this second step is to identify zones that require improved attention to emergencies from a logistics perspective. The third stage of the study consists in finding the minimum average travel time and real travel time; i.e. trips that last longer than 5 minutes and 6 minutes, respectively. To identify the zones that need AD or ESF, three variables (fatalities, LT emergencies, and population) with values between zero $(0)$ and ten $(10)$ were assessed. Zero $(0)$ indicates zones with no recorded events. Values between one (1) and ten (10) are given according to the decile, one (1) being the value for the zones in the first decile and 10 for those that are in the last decile according to the number of events. Variable values greater than five (5) indicate the need for AD or ESF. Finally, the fourth step, allows us to identify zones where an $\mathrm{AD}$ or an ESF can be located as: a) a zone that requires at least an $\mathrm{AD}$ or an ESF, b) a zone with a diameter of less than $3.0 \mathrm{~km}$, and c) a zone with significant road connections with the surrounding area.

\subsection{Calculation of Global Average Accessibility, Stage 5}

On this stage, an analysin on each great zone accessibility was made by means of the Kriging model application, first used by Georges Matheron in 1963. The geostatistical model is based on a Master's thesis of Krige (1951), an engineer who used it to predict mineral reserves. For spatial interpolation, geostatistical models were used to forecast count values at unmeasured locations while computing the errors of these predictions. To apply the model, it is necessary to know the coordinates of every node of the transport network of each great zone, and the average travel time from each node to every another node (operating characteristics of the transport network). In general, the predicted values are based on the principle that unobserved values points are autocorrelated over space. The autocorrelation declines with distance. Spatial variables could be defined as shown in Equation (2); the values for forecasting (average travel time) depend on observable causal factors (e.g., physical and operating characteristics of the road network, facility type). Where $\mathrm{Zi}(\mathrm{s})$ is the average travel time (target variable) and $\mathrm{s}$ is the location coordinates (x, y) of site i. $\mathrm{Zi}(\mathrm{s})$ is the sum of the deterministic trend $(\mathrm{s}), \mu(\mathrm{s})$ is an explanatory function of variables at location $\mathrm{i}$, and a spatially dependent error term $\varepsilon i(\mathrm{~s})$. The spatial autocorrelation level of the dataset relies on three semivariogram variables: the nugget effect, range, and sill (Wang \& Kockelman, 2009).

$$
Z_{i}(s)=\mu(s)+\varepsilon_{i}(s)
$$

The semivariogram characterizes the properties of spatial dependence between values of an observed sample dataset, which is calculated by Equation (3) (Giraldo, 2002), where $Z(x)$ is the value of the variable in a site with $x$, y coordinates. $\mathrm{Z}(\mathrm{x}+\mathrm{d})$ is another sample value separated by a distance $\mathrm{h}, \mathrm{n}$ is the number of couples that are separated by that distance $h$. It is emphasized that the model uses the shortest distance criterion to obtain better predictions for short distances between the nodes, meaning that the similarity or spatial correlation between the observations is greater (Giraldo, 2002; Wackernagel, 2003). This method has been used previously by researchers for issues such as demand prediction for public transport systems (Prasetiyowati, Imrona, Ummah, \& Sibaroni, 2016). The accessibility analysis leads to the final step, which is to identify the location of AD to fulfill the requirements of time in an identified great zone.

$$
\overline{\gamma_{(h)}}=\frac{\sum\left(Z_{(x+d)}-Z_{(x)}\right)^{2}}{2 n}
$$

\section{Results and Discussion}

\subsection{Colombia and Manizales: Inequality in the Geographical Distribution of ESF}

Law 100 of 1993 established that the Colombian health system is based on insurance companies known as EPS and 
health care facilities called IPS. The system sought equity by prompting enhanced coverage and use of healthcare facilities by dividing the population into two main categories of subsidized users and those who contribute to the system. The former are provided a system which is subsidized by the government and contributors, who have to make payments for their health insurance in accordance to their income level. However, this has been a controversial subject, as some people claim that the system fulfilled its goal in 2000 (Homedes \& Ugalde, 2005), while others claim that the goal has not yet been reached, and that medical services have been reduced (Ayala, 2014) through corruption and the fact that some IPS and EPS have faced bankruptcy (Molina et al., 2010; Molina \& Ramírez, 2013).

The operation of the health system is a close relationship between EPS and IPS. For instance, a patient who needs a medical appointment has to go to the IPS that has an agreement with the patient's EPS, and the health insurance company pays the IPS for the services provided. The operation changes when the patient has a Life-Threatening (LT) emergency, because they need to go to the nearest emergency service facility (ESF), whereas for a Non-Life-Threatening (NLT) emergency, the patient needs to go to an IPS that would provide for the EPS and patient's health requirements. Having only $48 \%$ of the world's registered vehicles, middle- and low-income countries report higher rates of road traffic mortality (around 90\%) (Peden et al., 2004).

Road traffic injuries have an important impact on economic development; a high percentage of road traffic fatalities involve 15 to 44 year old people, which means lower potencial on the productivity life of the population. (Ameratunga, Hijar, \& Norton, 2006). In Colombia, the leading cause of death is consistent with the main cause of death globally: ischemic heart disease, followed by cerebrovascular disease and respiratory infections (Moreno, 2017). Road traffic accidents represent the second external cause of death after homicides (Moreno, 2017). Thus, violence is a major public health problem, including road traffic accidents, categorized by LT or NLT. However, in such events, the expenses are paid by the SOAT (mandatory insurance for road traffic accidents). The SOAT insurance is paid for all motorized vehicles, and every ESF and fracture clinic has a contract with this insurance. The SOAT has become a profitable business for ESF, AD, Fracture Clinics, etc. (Federación Médica Colombiana [FMC], 2016). However, in many cases, the IPS do not attend the emergencies due to a deficient health system and a lack of regulation. Hence, the patients have to be transported to a different IPS, sometimes causing their death.

Colombia is divided into 6 regions: Amazon, Orinoquía, Pacific, Caribbean, Andes and Insular (See Figure 1). These regions contain a total of 32 provinces or departments, each with at least two IPS. For instance, the department of Vaupes has the lowest index of IPS per 100,000 inhabitants with 5, although its capital Mitú has 6 IPS per 100,000 inhabitants, this being the lowest index amongst capital cities. The highest index belongs to the department of Casanare with 35 IPS per 100,000 inhabitants. However, the highest index for capital cities is Quibdó, the main municipality of the department of Chocó, with 83 IPS per 100,000 inhabitants. According to the Emergency Service Facilities, the department of Atlántico has the lowest ESF with 1 per 100,000 inhabitants and the highest index belongs to the department of Amazonas with 13 ESF per 100,000 inhabitants. Among the capital cities of the 32 departments, Bogota, Arauca and Yopal only have 1 ESF per 100,000 inhabitants. Quibdó and Puerto Carreño have 6 ESF per 100,000 inhabitants, this being the highest index. Manizales has an index of 4 ESF per 100,000 inhabitants. Indicating that in Colombia, there is no standard index for IPS or ESF (Guzmán, 2014).

$39 \%$ of Manizales population lives in stratum 3, while $80 \%$ in 1 and 2 strata. Following other Latin American cities with predominance of low- and middle-income citizens. From the year 2010 to the year 2013, there were 14 ESF in Manizales and from 2014 to 2015, there were 13. The geographic distribution of these ESF throughout Manizales is a typical example of social inequality; strata 1 and 2 sectors have the lowest density of ESF facilities, while strata 5 and 6 (the richest) sectors have the highest density of ESF facilities, as shown in Table 1 (Government of Manizales, 2015). 
Table 1. Amount and density of Ambulance Dispatches and ESF by stratum

\begin{tabular}{lllllll}
\hline Stratum & $\begin{array}{l}\text { Ambulance } \\
\text { Dispatches }\end{array}$ & $\begin{array}{l}\text { Ambulance } \\
\text { Dispatches per } \\
\text { 100k inhabitants }\end{array}$ & $\begin{array}{l}\text { ESF } \\
\mathbf{2 0 1 0 - 2 0 1 3}\end{array}$ & $\begin{array}{l}\text { ESF } \\
\mathbf{2 0 1 4 - 2 0 1 5}\end{array}$ & $\begin{array}{l}\text { ESF per 100k } \\
\text { inhabitants } \\
\mathbf{2 0 1 0 - 2 0 1 3}\end{array}$ & $\begin{array}{l}\text { ESF } \\
\text { inhabitants } \\
\mathbf{2 0 1 4}-\mathbf{2 0 1 5}\end{array}$ \\
\hline 1 & 0 & 0 & 0 & 0 & 0 & 0 \\
2 & 1 & 1 & 1 & 1 & 1 & 1 \\
3 & 2 & 2 & 2 & 2 & 2 & 2 \\
4 & 1 & 2 & 3 & 3 & 5 & 5 \\
5 & 2 & 9 & 4 & 4 & 18 & 18 \\
6
\end{tabular}

Note. $\mathrm{ESF}=$ Emergency Service Facility. Source: Authors' own based on information from the local government of Manizales.

In relation with the location of Ambulance Dispatches (AD), there are 5 organizations that provide medical emergency services: the Red Cross, Fire Brigade, Civil Defence, GER (Special Group of Rescue) and BYR (Search and Rescue); all of them have one AD location and only the Fire brigade has two AD locations. Table 1 shows the social and health inequalities based on the lack of AD locations in low-income zones. In Manizales, the cause of emergencies attended by AD and ESF are external and include road traffic accidents, personal accidents, and accidents at home (Figure 3). With respect to health insurance used to attend the emergencies, the SOAT is predominant, given that road traffic accidents represent approximately $50 \%$ (See Figure 4) of the events in each year of the analysis. Between 2010 until 2015 (not including 2012, non-appearance of data), counting the first semester of each year, 7,475 emergencies occurred, and they were attended by an AD and transported to an ESF. There were 240 deaths and 201 of them happened in the location of the event. The remaining 39 died in the journey between the event and the ESF. With respect to the strata where the events were located, stratum 3 was where the highest amount of both LT and NLT emergencies occurred, whereas strata 5 and 6 were the ones where less number of events occurred (See Table 2).

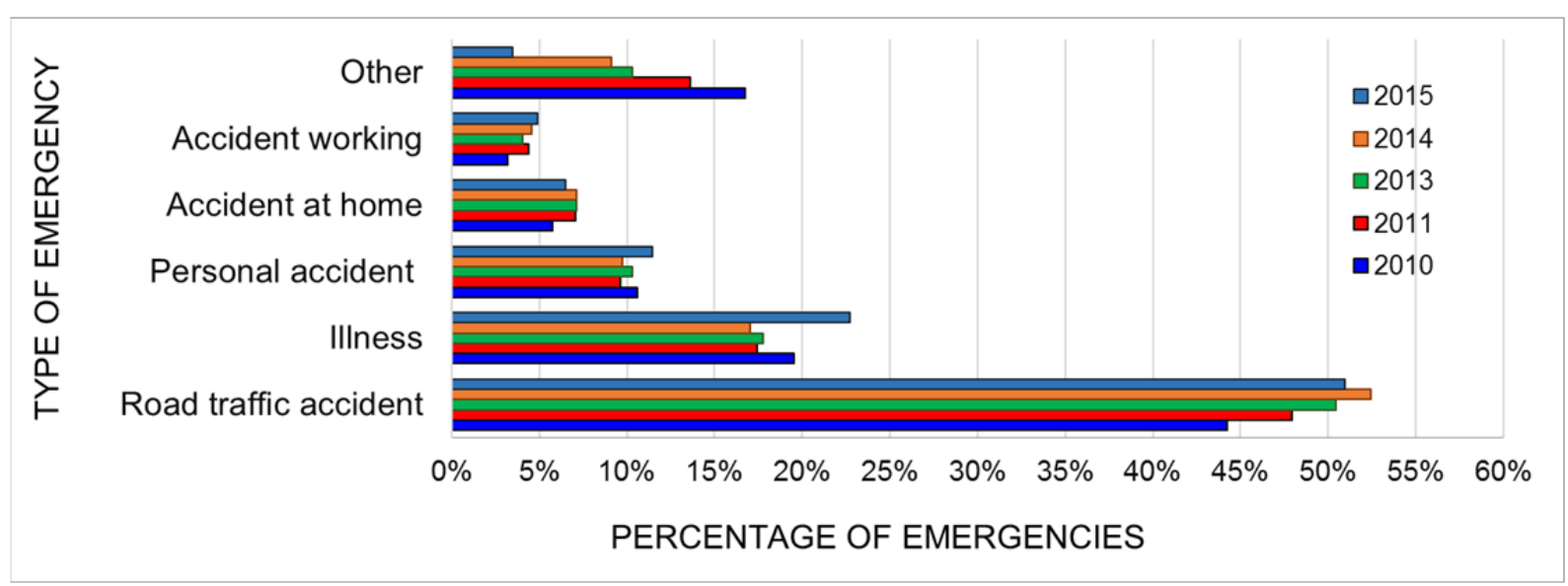

Figure 3. Types of emergencies attended by AD and ESF in the first semester between 2010 and 2015 excluding 2012. Source: Authors' own based on the Fire Brigade database 


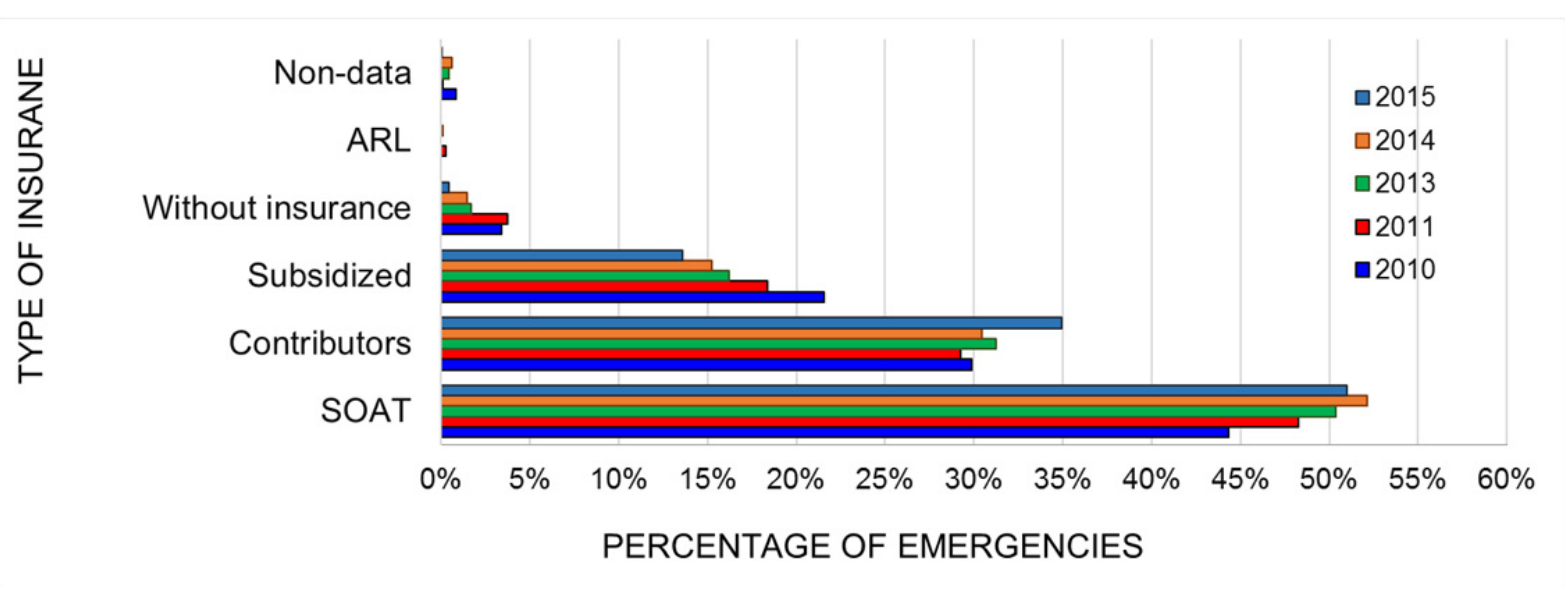

Figure 4. Type of health insurance of the patients attended in emergencies that occurred in the first semester from 2010 to 2015 excluding 2012. Source: Authors' own based on the Fire Brigade database

Table 2. Amount and density of Ambulance Dispatches and ESF by stratum

\begin{tabular}{lllllllllll}
\hline \multirow{2}{*}{ Stratum } & \multicolumn{1}{l}{ Life-Threatening } & \multicolumn{1}{c}{ Non-Life-Threatening } \\
\cline { 2 - 11 } & $\mathbf{2 0 1 0}$ & $\mathbf{2 0 1 1}$ & $\mathbf{2 0 1 3}$ & $\mathbf{2 0 1 4}$ & $\mathbf{2 0 1 5}$ & $\mathbf{2 0 1 0}$ & $\mathbf{2 0 1 1}$ & $\mathbf{2 0 1 3}$ & $\mathbf{2 0 1 4}$ & $\mathbf{2 0 1 5}$ \\
\hline 1 & 47 & 40 & 47 & 53 & 54 & 106 & 126 & 86 & 129 & 133 \\
2 & 91 & 46 & 78 & 74 & 60 & 166 & 170 & 120 & 210 & 189 \\
3 & 152 & 112 & 157 & 143 & 145 & 489 & 438 & 400 & 479 & 520 \\
4 & 81 & 63 & 88 & 74 & 83 & 200 & 196 & 189 & 190 & 229 \\
5 & 17 & 12 & 23 & 14 & 18 & 70 & 107 & 55 & 85 & 79 \\
6 & 18 & 16 & 31 & 25 & 27 & 74 & 66 & 64 & 112 & 109 \\
\hline Total & 406 & 289 & 424 & 383 & 387 & 1105 & 1103 & 914 & 1205 & 1259 \\
\hline
\end{tabular}

Source: Authors' own based on the Fire Brigade database.

\subsection{Life-Threatening Emergencies and Fatalities in Emergency Events: Geographical Decile Distribution}

According to the proposed research methodology, the journey time variable is the main variable used to identify the need for an AD or ESF in a zone. Secondary variables include population, casualties during amergency assistance, and Life-Threatening (LT) emergencies. Non-Life-Threatening (NLT) emergencies are not considered in this process, as in these cases a quick response is not required, which does not mean that NLT should not be attended as soon as they could be. Figure 5 illustrates the LT events (by decile) by neighborhood, where the CBD (Administrative Center) and peripheries are zones with high values. Figure 6 shows the fatality events, where the CBD is the zone with the highest values. LT events and fatalities are located in zones characterized by a high flow of pedestrians or high murder index (the case for CBD) and high vehicle speed (peripheria). In addition, external causes of death such as the other types of emergencies analyzed in this study should be taken in account. In accordance with the population, the CBD could be most critical due to LT and fatality events; however, in terms of transport time, it is a zone where AD and ESF are near. In 2016, however, this ESF stopped providing emergency services. Furthermore, it was located in a stratum 3 neighborhood. Hence, stratum 3 zones only have one ESF, demonstrating the inequalities in these services. 


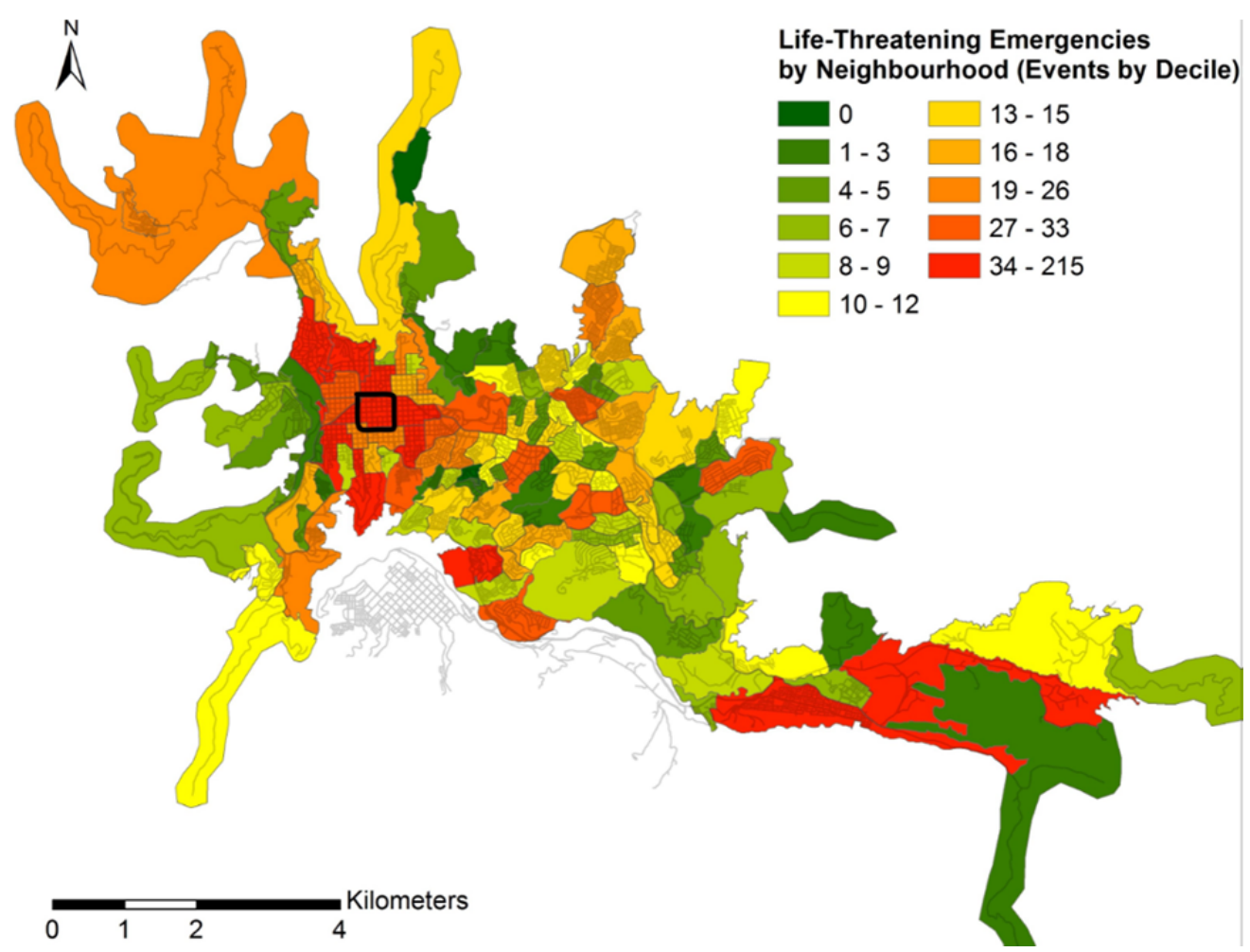

Figure 5. Life-threatening emergencies by neighborhood. Source: Authors' own elaboration based on Fire Brigade database

\subsection{Zones that Fulfill -or not-The Time Requirements for Attention to Emergency Events}

The obtained results show that in relation with the journey to ESF, nineteen (19) neighborhoods of one hundred and twenty-four (124) coply with the expected range of time, as there were more ESF than AD. Furthermore, the results show that nine (9) neighborhoods (see Figure 7) comply with the requirements of AD to emergency event journey time ( 5 minutes). However, the results are unsatisfactory because the travel time requirements are unfulfilled for over $85 \%$ of the neighborhoods. The results show that for the journey from the AD to the emergency event, $48.4 \%$ (60 of 124) of the neighborhoods did not comply with any of the travel time requirements (See Figure 8); and for the journey from the emergency event to the ESF, 29.8\% (37) of them were in the same situation as AD. In fact, the peripheral neighborhoods are characterized by the non-fulfillment of the minimum average travel time and the shown average travel time. The quality serice provided to almost half the city does not comply with the expected standards in terms of response travel time related to $\mathrm{AD}$; hence, $\mathrm{AD}$ requires more planning by policy makers.

Nevertheless, travel time responses to ESF are better than they are to AD, and consideration is required in order to enhance the population quality of life by means of grater accessibility to emergency health services. A logical hypothesis could be that most zones near the $\mathrm{ESF}$ or $\mathrm{AD}$, meet with travel time requirements if the medical emergencies occur inside each neighborhood and these are attended by the nearest facility (ESF or AD). However, analyzing the results shown in Figure 9, we can conclude that 44.4\% (55) of the neighborhoods do not comply with the travel time conditions for the AD to emergency event journey, whereas for the event - ESF travel time, 52.4\% (65) of the neighborhood fulfills this condition. 


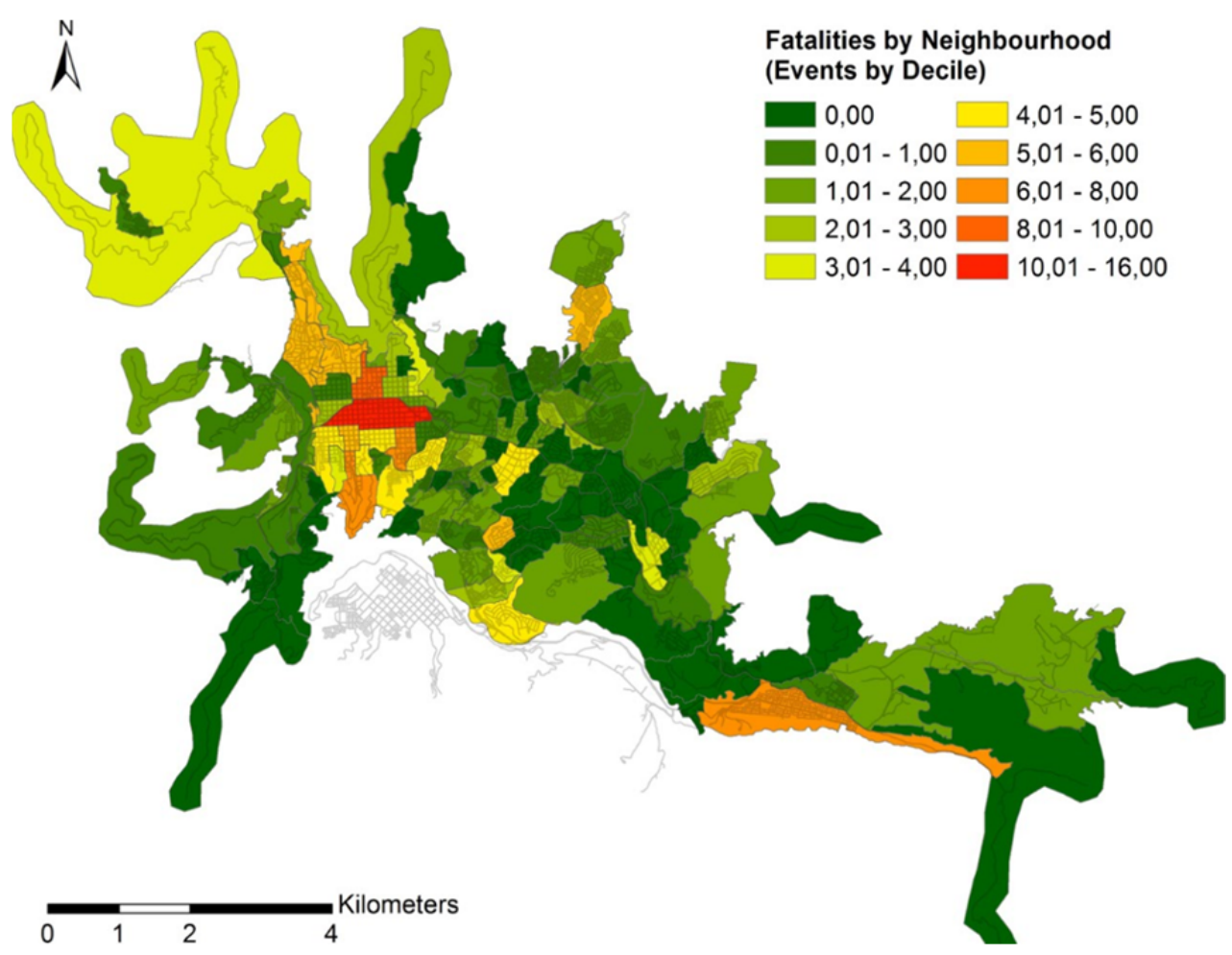

Figure 6. Fatalities by neighborhood in attention to emergencies. Source: Authors' own elaboration based on Fire Brigade database

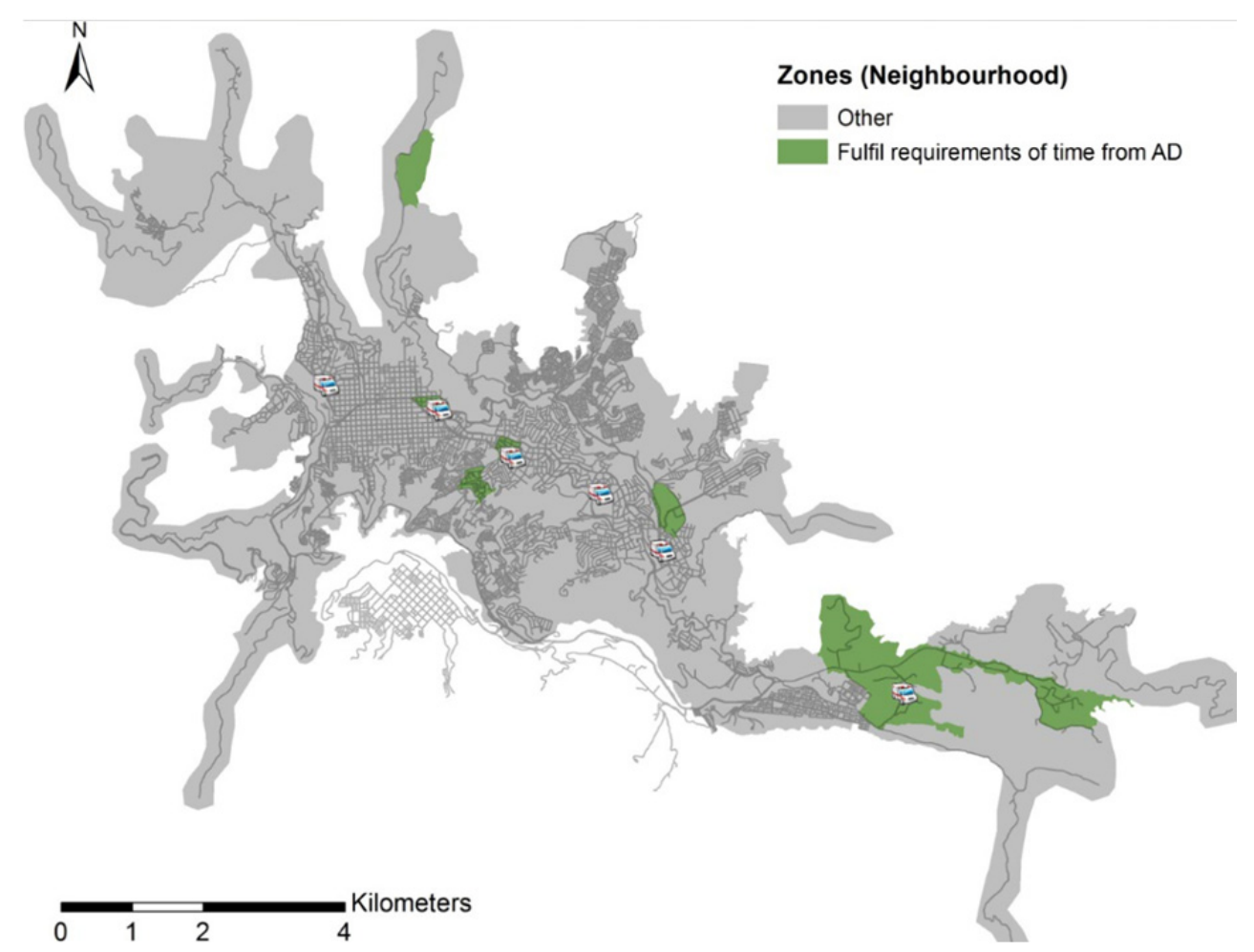

Figure 7. Neighbourhoods which fulfill AD to event time requirements. Source: Authors' own elaboration based on Fire Brigade database

Hence, these neighborhoods need to improve their logistics in terms of attention to emergencies. We can conclude that the Fire Brigade together with Manizales local government must take action to attend to the emergencies and 
transport patients to ESF in optimal travel time, seeking to decrease the social inequalities and enhance emergency medical services.

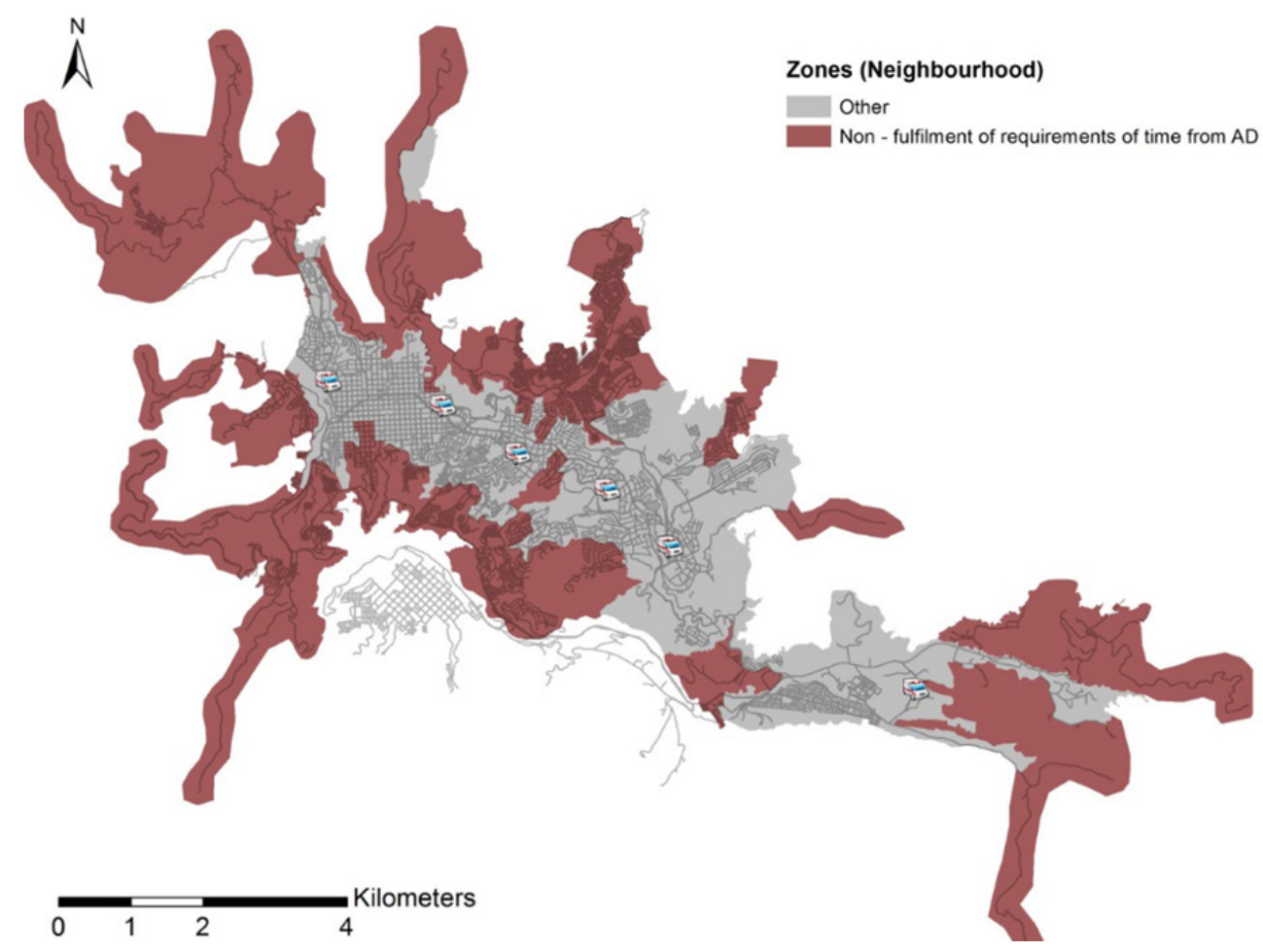

Figure 8. Neighborhoods which do not fulfill travel time requirements between AD - event. Source: Authors' own elaboration based on Fire Brigade database

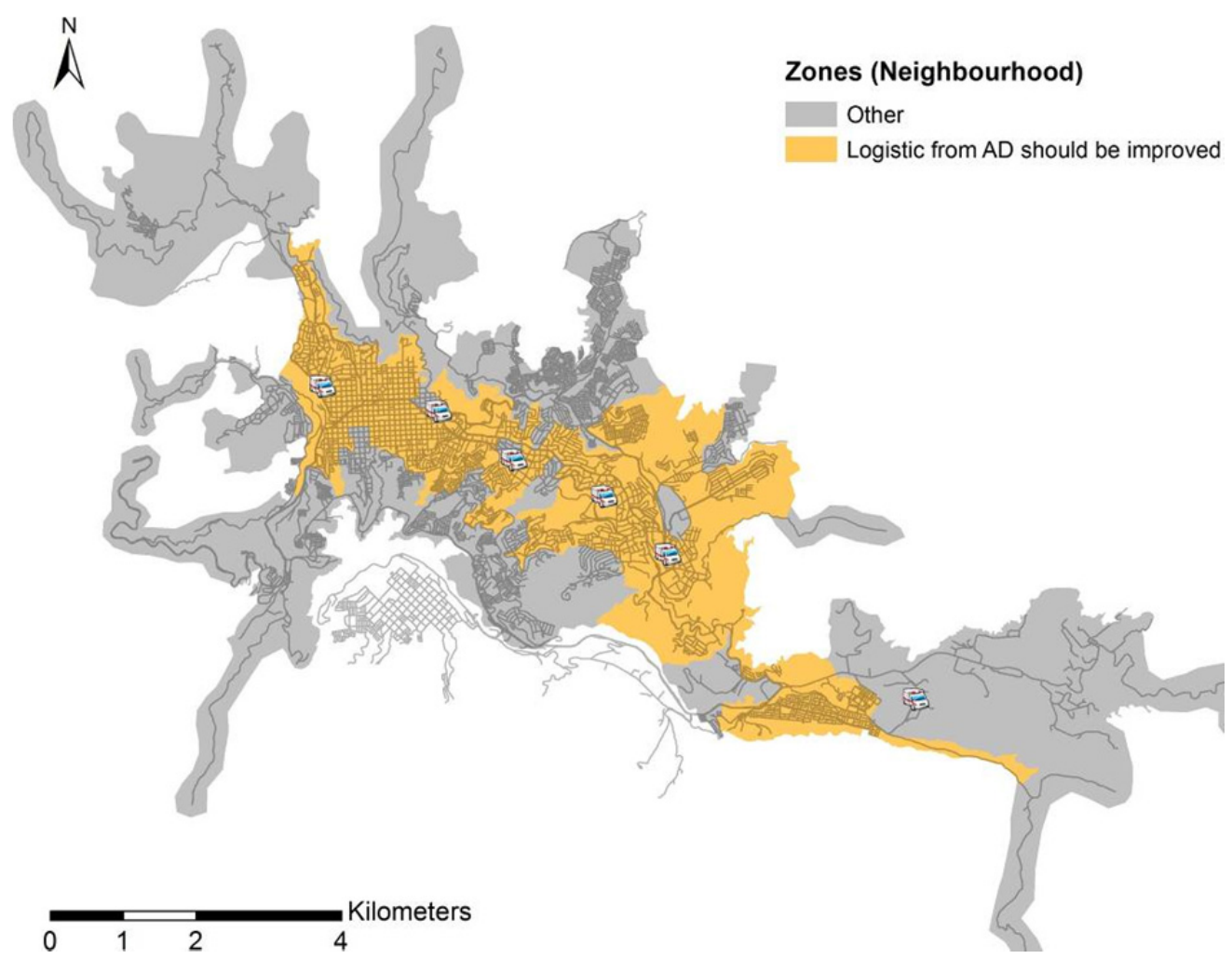

Figure 9. Neighborhoods where the logistics relating to attention to emergency events must be enhanced in terms of the AD to emergency event journey. Source: Authors' own elaboration based on Fire Brigade database 


\subsection{Identification of Zones Where AD or ESF Are Needed and Their Location According to Optimal Travel Time}

All zones in which it is impossible to attend to emergencies in optimal time (response time and transport time), should improve the average of at least one of the three variables (population, life-threatening emergencies and deaths) to be identified as zones where facilities (AD or ESF) are required. Hence, 33 of the 60 zones where the optimal time between $\mathrm{AD}$ and event do not fulfill the need for an $\mathrm{AD}$ (See Figure 10), representing the $27 \%$ of the neighborhoods. Distributed as mentioned below: One (1) zone is diagnosed by deaths and life-threatening emergencies; three (3) zones are diagnosed only by life-threatening emergencies; three (3) zones are diagnosed by deaths, life-threatening emergencies and population; thirteen (13) zones are diagnosed just by population; and thirteen (13) zones are diagnosed by population and life-threatening emergencies.

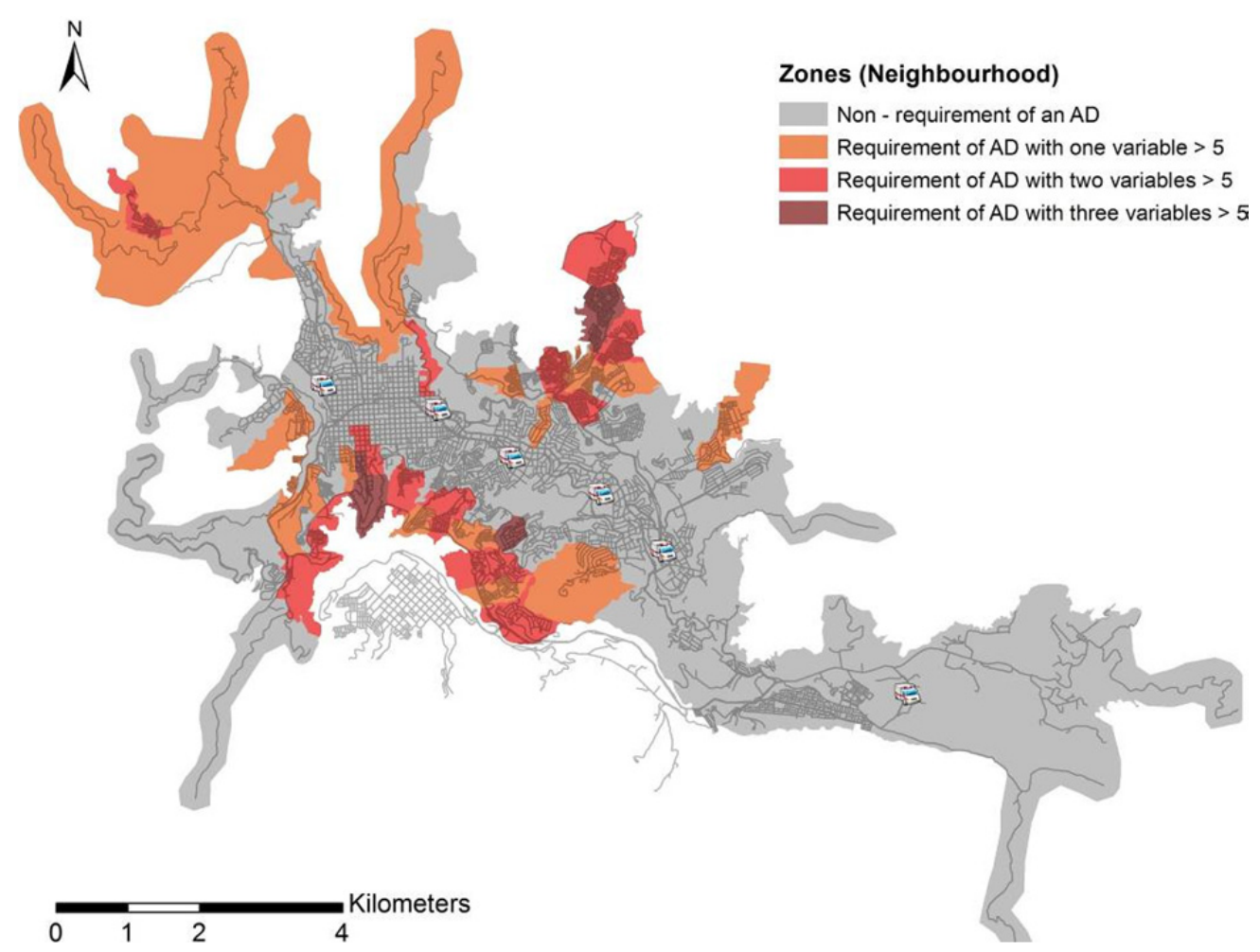

Figure 10. Neighborhoods where AD is needed. Source: Authors' own based on Fire Brigade DANE and Manizales local government databases

This research found that 20 neighborhoods of the 37 zones that did not comply with the 6 min range of time necessary to attend an emergency in the proper maner, would need the implementation of ESF. Representing 16\% of the neighborhoods. These 20 zones are distributed according to the three variables as mentioned below: One (1) zone is diagnosed by deaths and life-threatening emergencies; one (1) zone is diagnosed by deaths, life-threatening emergencies and population; two (2) zones are diagnosed only by life-threatening emergencies; six (6) zones are diagnosed only by population; and ten (10) zones are diagnosed by population and life-threatening emergencies. In sum, the population variable holds the greatest weight when diagnosing the zones where a facility is required (29 zones where an $\mathrm{AD}$ in needed and 17 neighborhoods where $\mathrm{ESF}$ are required). This is followed by life-threatening emergencies (20 zones where an AD is needed and 14 neighborhoods where ESF are required). Twenty-two of the sectors were not classified as a zone where an $\mathrm{AD}$ is needed, and $14 \%$ of the neighborhoods were not catalogued as zones where an ESF is required. However, these sectors could benefit from being near to a zone that is classified as a neighborhood where a facility to generate equity in accessibility to emergency medical services is essential. According to the characteristics to define the great zones, this research found 8 zones of analysis to identify the best location to operate an AD (See Figure 11) and for ESF, 6 zones of analysis were found. Furthermore, these six zones for ESF coincide with zones of analysis for AD to a great extent. It means that the ESF could be built where the $\mathrm{AD}$ would be located. In addition, these zones of analysis are in the periphery, demonstrating spatial inequalities, where low-income groups live.

As an example to explain the methodology in each zone defined, we use one zone of analysis which requires $\mathrm{AD}$ 
and ESF as shown in Figure 12, identifying that the zone of analysis is not only made up by neighborhoods where ESF or AD are needed, given that they must also have good road connectivity. Hence, for this zone of analysis, we included four (4) neighborhoods which fulfill attention to emergencies in minimum travel time. According to its diameter $(3 \mathrm{~km})$, this zone of analysis satisfied the requirement, and, even though it has a diameter of $1.6 \mathrm{~km}$, it is conditioned by road connectivity as shown in Figure 12 in the west and east of the zone of analysis.

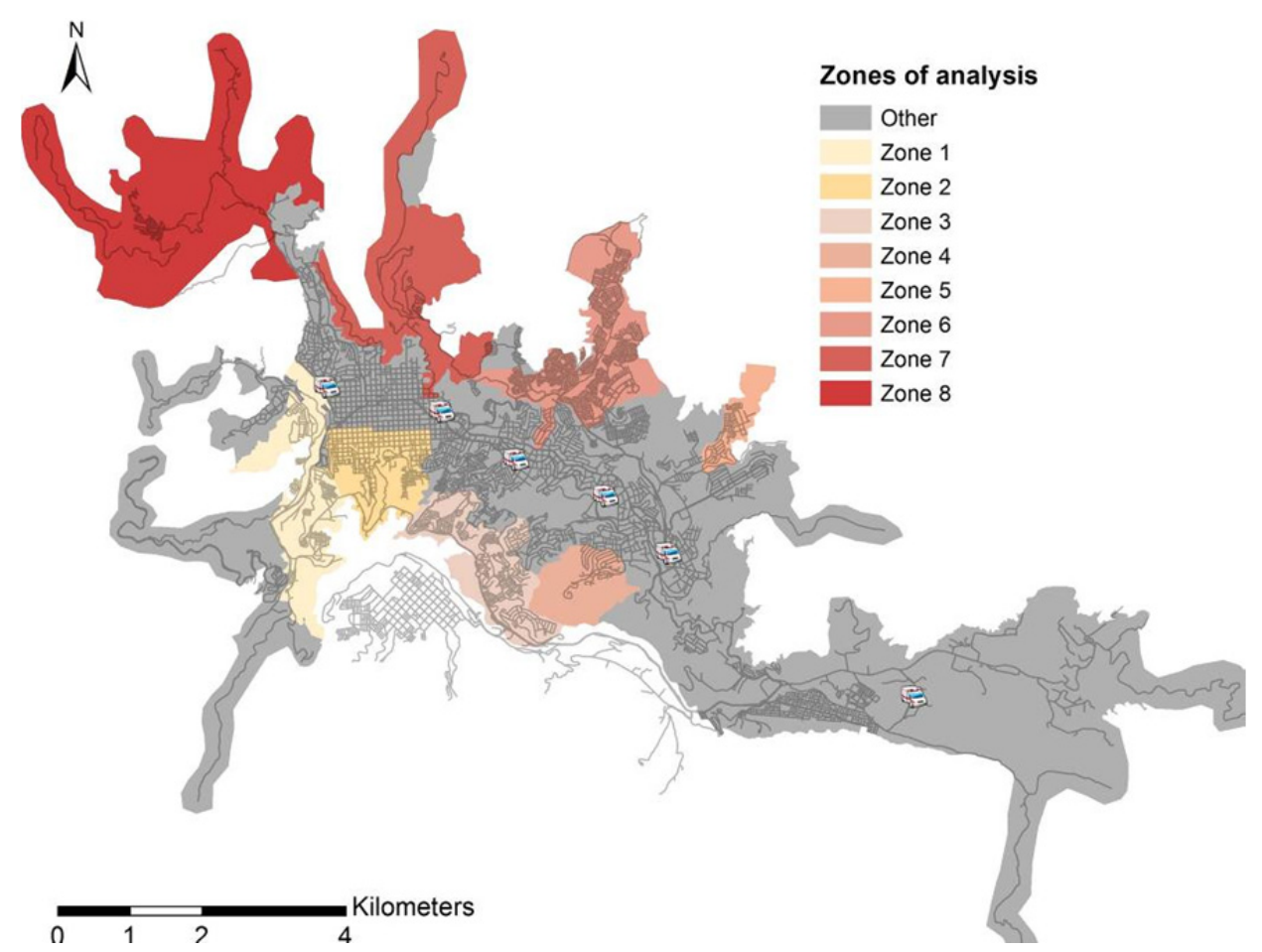

Figure 11. Zones of analysis where ADs would be located. Source: Authors' own

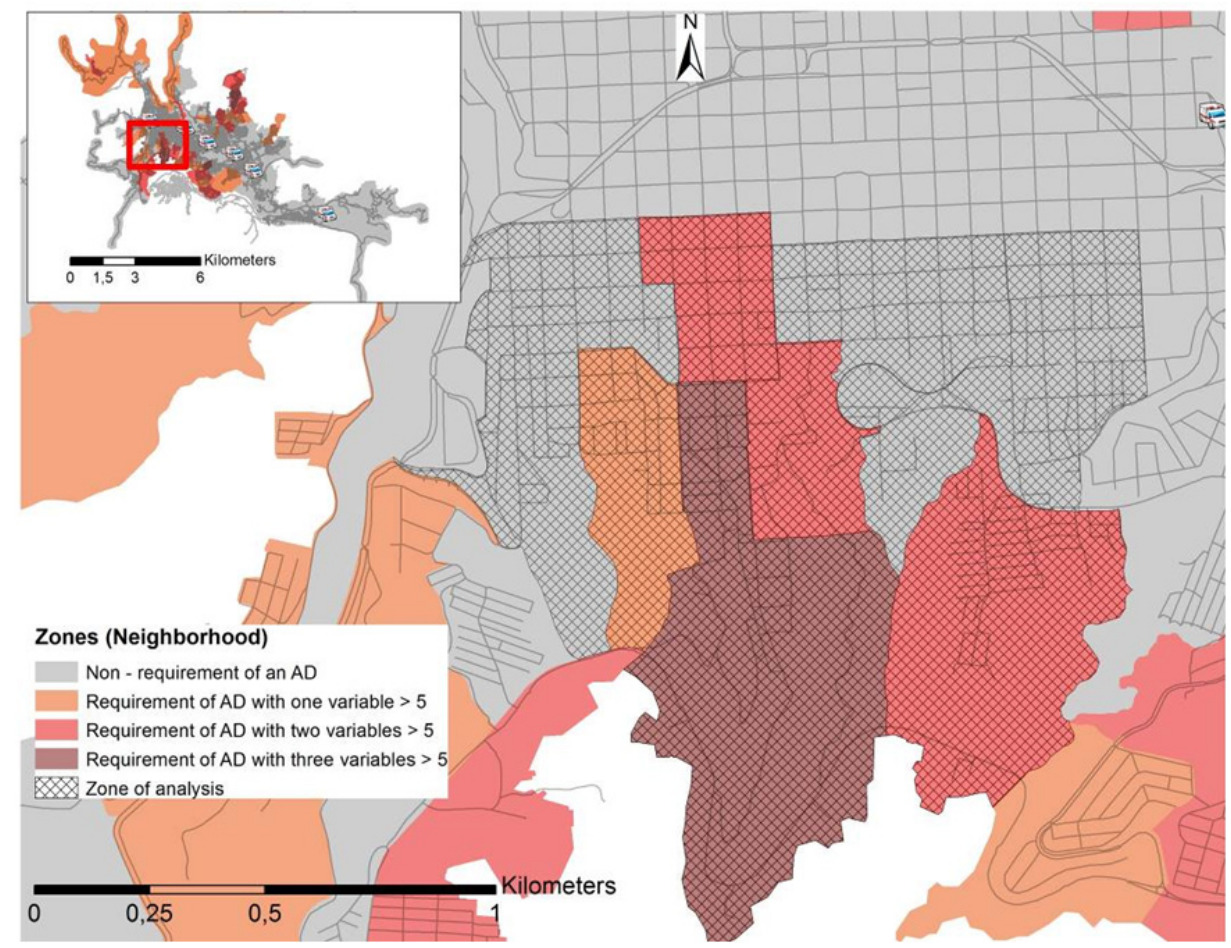

Figure 12. Example of a zone of analysis where the AD would be located. Source: Authors' own 
The accessibility analysis for the great zone shown in Figure 12 is illustrated in Figure 13, which shows the exact sector in which the facility must be developed. For instance, if an ESF or AD operates in the sector proposed, the time required to attend to emergencies would be, on average, 3.5 minutes. In addition, these facilities supply a low-income sector. However, they could be located in a zone where the average response time is less than 5 min and the average transport time is less than $6 \mathrm{~min}$. This infers that there is a great area with reference to which the government can decide the location according to land use. Note: This paper only shows the figures corresponding to the analysis of ambulance dispatches. The graphics of the analysis of emergency service facilities has not been shown due to the extension of the paper.

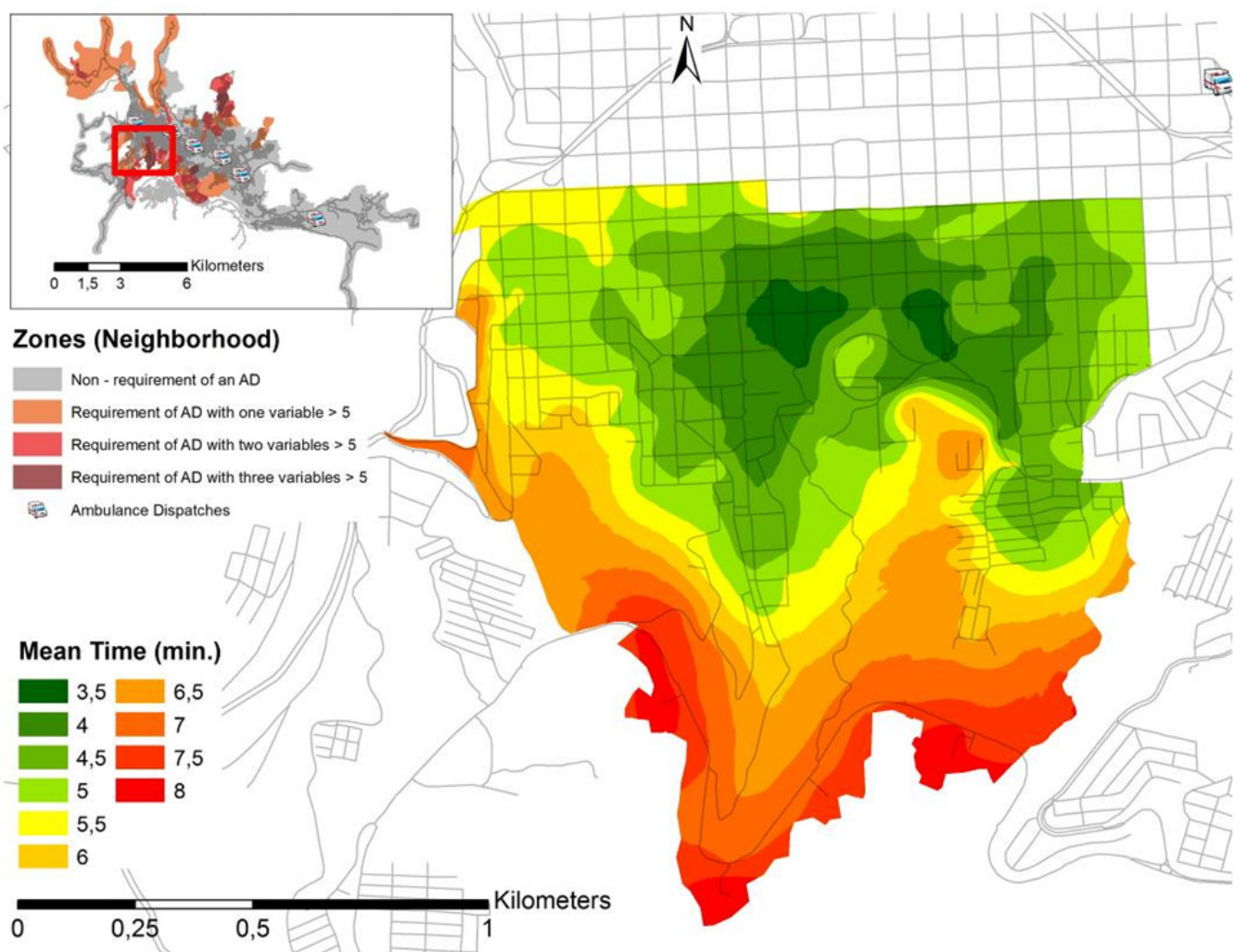

Figure 13. Example of an analysis of accessibility to identify the location of AD to fulfill the time requirements in a zone of analysis. Source: Authors' own

\section{Conclusion}

Currently, given the operational characteristics of the transportation network, as well as medical emergency events recorded during the study period, there is clear inequity in the provision of this type of health service, fact that must be taken into account in future Territorial Management Plans (POT). Thus, and based on the results of this study, Manizales needs an improved spatial coverage of ESF and AD in order to foster equity, considering that the populations proximity to such facilities influence health contitions in emergency events.

With the proposed research methodology, the results show that there is correlation between longer pre-hospital time and living in a low-income neighborhoods. This conclusion would help to ensure equity in access to emergency medical services through improvements in the logistic performance of emergency medical attention. Hence, the application of the research methodology would help to reduce mortalities in medical emergencies, understanding that in terms of transport time, $5 \mathrm{~min}$ as a target limit of time is a good standard regardless of whether the emergency is a cardiac arrest, trauma or a stroke.

If the main research target is to provide planning tools to obtain equity in attention to medical emergencies, this would constitute a great step towards iniciation of the construction of an ESF, avoiding health inequalities through an adequate distribution of resource investment in ESF, $\mathrm{AD}$ and transport networks, considering that low-income inhabitants use the health care services more, seeking to bring about equality in relation with high income groups.

One of the research limitations is the operating speed used to compute average travel time to each medical 
emergency event. This is due to the fact that the database reflects the average speed of the different transport modes over the network. Therefore, in future research, it may be helpful to consider the speed of emergency vehicles only.

\section{Acknowledgments}

The study was made possible thanks to the support lent by the School of Engineering and Architecture at Nacional University of Colombia in Manizales, who supported its execution by means of the research announcement 2013-2015, research code 28588. The authors especially thank the Manizales Fire Brigade; PhD. Daniel Oviedo form the Development Planning Unit at University College of London, and the Research Group in Sustainable Mobility of the Civil Engineering Department. Special thanks do to Manuela Ramírez Marín, MD at Universidad Javeriana.

\section{Competing Interests Statement}

The authors declare that there are no competing or potential conflicts of interest.

\section{References}

Ameratunga, S., Hijar, M., \& Norton, R. (2006). Road-traffic injuries: confronting disparities to address a global-health problem. The Lancet, 367(9521), 1533-1540. https://doi.org/10.1016/S0140-6736(06)68654-6

Apparicio, P., Gelb, J., Dubé, A.S., Kingham, S., Gauvin, L., \& Robitaile, É. (2017). The approaches to measuring the potential spatial access to urban health services revisited: distance types and aggregation-error issues. International Journal of Health Geographics, 16(32), 1-24. https://doi.org/10.1186/s12942-017-0105-9

Ayala, J. (2014). La salud en Colombia: más cobertura pero menos acceso. Banco de la República, Centro de Estudios Económicos Regionales. http://www.banrep.gov.co/docum/Lectura_finanzas/pdf/dtser_204.pdf

Batty, M. (2009). Accessibility: in search of a unified theory. Environment and Planning B: Planning and Design, 36, 191-194. https://doi.org/10.1068/b3602ed

Bauer, J., Muller, R., Bruggmann, D., \& Groneberg, D. A. (2017). Spatial Accessibility of Primary Care in England: A Cross - Sectional Study Using a Floating Catchment Area Method. Health Services Research. https://doi.org/10.1111/1475-6773.12731

Biggs, B., King, L., Basu, S., \& Stuckler, D. (2010). Is wealthier always healthier? The impact of national income level, inequality, and poverty on public health in Latin America. Social Science \& Medicine, 71(2), $266-273$. https://doi.org/10.1016/j.socscimed.2010.04.002

Blackwell, T. H., \& Kaufman, J. S. (2002). Response time effectiveness: Comparison of response time and survival in an urban emergency medical services system. Acadademic Emergency Medicine, 9(4), $288-295$. https://www.ncbi.nlm.nih.gov/pubmed/11927452

Braveman, P., \& Gruskin, S. (2003). Poverty, equity, human rights and health. Bulletin of The World Health Organization, 81(7), 539-545. https:/www.ncbi.nlm.nih.gov/pmc/articles/PMC2572503/pdf/12973647.pdf

Brown, D.L., Schneider, D.L., Colbert, R., \& Guss, D. (1998). Influence of insurance coverage on delays in seeking emergency care in patients with acute chest pain. The American Journal of Cardiology, 82(3), 395-398. https://doi.org/10.1016/S0002-9149(98)00338-5

Calcuttawala, Z. (2006). Landscapes of information and consumption: A location analysis of public libraries. In Calcutta. E. D. Garten, D. E. Williams, \& J. M. Nyce (Eds.), (vol. 24, pp. 319-388).

Carr, B. G., Caplan, J. M., Pryor, J. P., \& Branas, C. C. (2006). A Meta-Analysis of Prehospital Care Times for Trauma. Prehospital Emergency Care, 10(2), 198-206. https://doi.org/10.1080/10903120500541324

Cirino, S., Gonzalves, L. A., Gonzalves, M. B., \& Souza de Cursi, E. (2018). Modelo não linear de localização de instalações de serviços de saúde com indicador de acessibilidade incorporado. Cadernos de Saúde Pública, 34(3), 1-12. https://doi.org/10.1590/0102-311X00185615

Chardon, A. C. (2008). Reasentamiento y hábitat en zonas urbanas, una reflexión en Manizales. Cuadernos de $\begin{array}{lllll}\text { Vivienda } y & \text { Urbanismo, } & \text { 1(2), } & \text { 226-247. } & \text { Retrieved }\end{array}$ http://revistas.javeriana.edu.co/index.php/cvyu/article/viewFile/5491/4578

Cheng, J., Bertolini, L., \& le Clerq, F. (2007). Measuring sustainable accessibility. Transportation Research Record: Journal of the Transportation Research Board, 2017, 16-25. https://doi.org/10.3141/2017-03.

Cheng, G., Zeng, X., Duan, L. Lu, X., Sun, H., Jiang, T., \& Li, Y. (2016). Spatial difference analysis for accessibility to high level hospitals based on travel time in Shenzhen, China. Habitat International, 53, 
485-494. http://dx.doi.org/10.1016/j.habitatint.2015.12.023

Cone, D. C. (2004). Delaying defibrillation to give basic cardiopulmonary resuscitation to patients with out-of-hospital ventricular fibrillation. Annals of Emergency Medicine, 43(2), 296-297. https://doi.org/10.1016/j.annemergmed.2003.10.025

Cromley, E. K., \& McLafferty, S. L. (2011). GIS and public health (2nd ed.). Guilford Press editor.

Dijkstra, E. W. (1959). A note on two problems in connexion with graphs. Numerische mathematik, 1(1), 269-271. https://doi.org/10.1007/BF01386390

Dollar, D., \& Kraay, A. (2002). Growth is Good for the Poor. Journal of Economic Growth, 7(3), 195-225. https://doi.org/10.1023/A:1020139631000

Escobar, D. A., Holguin, J. M., \& Zuluaga, J. D. (2016). Accesibilidad de los centros de ambulancias y hospitales prestadores del servicio de urgencias y su relación con la inequidad espacial. Caso de estudio ManizalesColombia. Revista Espacios, 37(20), 20. http://www.revistaespacios.com/a16v37n20/16372020.html

Farrington, J., \& Farrington, C. (2005). Rural accessibility, social inclusion and social justice: towards conceptualization. Journal of Transport Geography, $13(1), \quad 1-12$. https://doi.org/10.1016/j.jtrangeo.2004.10.002.

Fawcus, S., Mbizvo, M., Lindmark, G., \& Nyström, L. (1997). A community-based investigation of maternal mortality from obstetric haemorrhage in rural Zimbabwe. Maternal Mortality Study Group. Tropical Doctor, 27(3), 159-163. https://doi.org/10.1177/004947559702700314

Federación Médica Colombiana [FMC]. (2016). "Guerra de ambulancias", cara macabra de los fraudes al Soat. Bogota. Retrieved from http://www.federacionmedicacolombiana.org/?q=node/1184

Field, J., Hazinski, M., Sayre, M., Chameides, L., Schexnayder, S., Hemphill, R., ...Vanden Hoek, T. L. (2010). Part 1: Executive Summary: 2010 American Heart Association guidelines for cardiopulmonary resuscitation and emergency cardiovascular care. Circulation, 122(3), S640-S656. https://doi.org/10.1161/CIRCULATIONAHA.110.970889

Foraker, R. E., Rose, K. M., McGinn, A. P., Suchindran, C. M., Goff, D. C., Whitsel, E. A., ... \& Rosamond, W. D. (2008). Neighborhood income, health insurance, and prehospital delay for myocardial infarction: the atherosclerosis risk in communities study. Archives of Internal Medicine, 168(17), 1874-1879. https://doi.org/10.1001/archinte.168.17.1874

Freimark, D., Matetzky, S., Leor, J., Boyko, V., Barbash, I. M., Behar, S., \& Hod, H. (2002). Timing of aspirin administration as a determinant of survival of patients with acute myocardial infarction treated with thrombolysis. American Journal of Cardiology, 89(4), 381-385.

Geurs, K. \& Van Wee, B. (2004). Accessibility evaluation of land-use and transport strategies: review and research directions. Journal of Transport Geography, 12(2), 127-140. https://doi.org/10.1016/j.jtrangeo.2003.10.005

Giraldo, R. (2002). Introducción a la geoestadística: Teoría y aplicación. Universidad Nacional de Colombia, Colombia, Bogotá, Colombia.

Goverment of Manizales. (2015). IPS Mixta - Publicas - Privadas. Municipio de Manizales. http://manizalessalud.com/servicios_salud/

Gulhan, G., Ceylan, H., Özuysal, M., \& Ceylan, H. (2013). Impact of utility-based accessibility measures on urban public transportation planning: A case study of Denizli, Turkey. Cities, 32, 102-112. https://doi.org/10.1016/j.cities.2013.04.001

Guzmán, K. (2014). Radiografia de la oferta de servicios de salud en Colombia. Banco de la República, Centro de Estudios Económicos Regionales. Retrieved from http://www.banrep.gov.co/docum/Lectura_finanzas/pdf/dtser_202.pdf

Gwatkin, D. R., Bhuiya, A., \& Victora, C. G. (2004). Making health systems more equitable. Lancet, 364(9441), 1273-1280. https://doi.org/10.1016/S0140-6736(04)17145-6

Hacke, W., Kaste, M., Bluhmki, E., Brozman, M., Dávalos, A., Guidetti, D., ... \& Schneider, D. (2008). Thrombolysis with alteplase 3 to 4.5 hours after acute ischemic stroke. New England Journal of Medicine, 359(13), 1317-1329. https://doi.org/10.1056/NEJMoa0804656

Hansen, W. G. (1959). How accessibility shapes land use. Journal of the American Institute of Planners, 25(2), 73-76. https://doi.org/10.1080/01944365908978307 
Higgs, G. (2009). The role of GIS for health utilization studies: Literature review. Health Services and Outcomes Research Methodology, 9(2), 84-99. https://doi.org/10.1007/s10742-009-0046-2

Higgs, G. (2004). A literature review of the use of GIS-based measures of access to health care services. Health Services and Outcomes Research Methodology, 5(2), 119-139. https://doi.org/10.1007/s10742-005-4304-7

Holl, A. (2007). Twenty years of accessibility improvements. The case of the Spanish motorway building programme. Journal of Transport Geography, 15, 286-297, doi:10.1016/j.jtrangeo.2006.09.003.

Homedes, N., \& Ugalde, A. (2005). Why neoliberal health reforms have failed in Latin America. Health Policy, 71(1), 83-96. https://doi.org/10.1016/j.healthpol.2004.01.011

Jauch, E. C., Cucchiara, B., Adeoye, O., Meurer, W., Brice, J., Gentile, N., \& Hazinski, M. F. (2010). Part 11: Adult Stroke. Circulation, 122(18 suppl 3), S818-S828. https://doi.org/10.1161/CIRCULATIONAHA.110.971044

Langford, M., Higgs, G., \& Fry, R. (2016). Multi-modal two-step floating catchment area analysis of primary health care accessibility. Health \& Place, 38, 70-81. https://doi.org/10.1016/j.healthplace.2015.11.007

Mathers, C. D., \& Loncar, D. (2006). Projections of Global Mortality and Burden of Disease from 2002 to 2030. Public Library of Science, 3(11), e442. https://doi.org/10.1371/journal.pmed.0030442

Marmot, M., Allen, J., Bell, R., \& Goldblatt, P. (2012). Building of the global movement for health equity: from Santiago to Rio and beyond. Lancet, 379(9811), 181-8. https://doi.org/10.1016/S0140-6736(11)61506-7

McCoy, C.E., Menchine, M., Sampson, S., Anderson, C., \& Kahn, C. (2013). Emergency Medical Services Out-of-Hospital Scene and Transport Times and Their Association With Mortality in Trauma Patients Presenting to an Urban Level I Trauma Center. Annals of Emergency Medicine, 61(2), 167-174. https://doi.org/10.1016/j.annemergmed.2012.08.026

Molina Marín, G., Vargas Jaramillo, J., Muñoz Echeverri, I. F., Acosta Gómez, J. J., Sarasti Vanegas, D., Higuita Higuita, Y., ... \& Cáceres Manrique, F. D. M. (2010). Dilemas en las decisiones en la atención en salud. Ética, derechos y deberes constitucionales frente a la rentabilidad financiera en el sistema de salud colombiano. Revista Gerencia y Políticas de Salud, 9(18). Retrieved from http://www.scielo.org.co/pdf/rgps/v9n18s1/v9n18s1a10.pdf

Molina, G., \& Ramírez, A. (2013). Conflicto de valores en el sistema de salud de Colombia: entre la economía de mercado y la normativa constitucional. Revista Panamericana de Salud Publica, 33(4), 287-293. https://scielosp.org/pdf/rpsp/2013.v33n4/287-293/es

Moreno, S. (2017). Forensis 2016: Datos para la vida, Herramienta para la interpretación, intervención y prevención de lesiones de causa externa en Colombia. Instituto Nacional de Medicina Legal y Ciencias Forenses. Retrieved from http://www.acotaph.org/assets/forensis-2016.pdf

Nakamura, T., Nakamura, A., Mukuda, K., Harada, M., \& Kotani, K. (2017). Potential accessibility scores for hospital care in a province of Japan: GIS-based ecological study of the two-step floating catchment area method and the number of neighborhood hospitals. BioMed Central Health Services Research, 17(438), 1-7. DOI 10.1186/s12913-017-2367-0

Neutens, T. (2015). Accessibility, equity and health care: Review and research directions for transport geographers. Journal of Transport Geography, 43, 14-27. http://dx.doi.org/10.1016/j.jtrangeo.2014.12.006

O'Connor, R. E., Bossaert, L., Arntz, H. R., Brooks, S. C., Diercks, D., Feitosa-Filho, G., ... \& Welsford, M. (2010). Part 9: Acute Coronary Syndromes. Circulation, $122(16$ suppl 2), S422-S465. https://doi.org/10.1161/CIRCULATIONAHA.110.985549

Prasetiyowati, S.S., Imrona, M., Ummah, I., \& Sibaroni, Y. (2016). Prediction of Public Transportation Occupation Based on Several Crowd Spots Using Ordinary Kriging Method. Journal of Innovative Technology and Education, 3(1), 93-104. http://doi.org/http://dx.doi.org/10.12988/jite.2016.6723

Peden, M., Scurfield, R., Sleet, D., Mohan, D., Hyder, A. A., Jarawan, E., et al. (2004). World report on road traffic injury prevention. World Health Organization. Retrieved from http://apps.who.int/iris/bitstream/10665/42871/1/9241562609.pdf

Pons, P. T., Haukoos, J. S., Bludworth, W., Cribley, T., Pons, K. A., \& Markovchick, V. J. (2005). Paramedic response time: Does it affect patient survival? Academic Emergency Medicine, 12(7), 594-600. http://doi.wiley.com/10.1197/j.aem.2005.02.013

Preston, J., \& Raje, F. (2007). Accessibility, mobility and transport-related social exclusion. Journal of Transport 
Geography, 15(3), 151-160. https://doi.org/10.1016/j.jtrangeo.2006.05.002

Sasson, C., Rogers, M. A., Dahl, J., \& Kellermann, A. L. (2010). Predictors of Survival from Out-of-Hospital Cardiac Arrest: a systematic review and meta-analysis. Circulation Cardiovascular Quality and Outcomes, 3(1), 63-81. https://doi.org/10.1161/CIRCOUTCOMES.109.889576

Shaikh, M. A., \& Ali, M. S. (2016). Spatial distribution and accessibility to public sector tertiary care teaching hospitals in Karachi: A Geographic Information Systems application. The Journal of the Pakistan Medical Association, 66(7), 889-892. https://www.ncbi.nlm.nih.gov/pubmed/27427142

Ulak, M. B., Kocatepe, A., Ozguven, E. E., Horner, M. W., \& Spainhour, L. (2017). Geographic Information System-Based Spatial and Statistical Analysis of Severe Crash Hotspot Accessibility to Hospitals. Transportation Research Record: Journal of the Transportation Research Board, 2635, 90-97. http://dx.doi.org/10.3141/2635-11

United Nations Development Programme. (2005). Human Development Report 2005: International cooperation at a crossroads. Aid, trade and security in an unequal world. New York: United Nations Development Programme. Retrieved from http://hdr.undp.org/sites/default/files/reports/266/hdr05_complete.pdf

Varghese, M., Sasser, S., Kellermann, A., \& Lormand J-D. (2005). Prehospital trauma care systems. Retrieved from http://www.who.int/iris/handle/10665/43167

Wang, X., \& Kockelman, K. (2009). Forecasting Network Data: Spatial Interpolation of Traffic Counts from Texas Data. Transportation Research Record: Journal of the Transportation Research Board, 2105, 100-108. https://doi.org/10.3141/2105-13

Wackernagel, H. (2003). Multivariate geostatistics: an introduction with applications. Springer Science \& Business Media. Berlin, Germany.

Yang, J., \& Mao, L. (2018). Understanding temporal change of spatial accessibility to healthcare: An analytic framework for local factor impacts. Health \& Place, 51, 118-124. https://doi.org/10.1016/j.healthplace.2018.03.005

\section{Copyrights}

Copyright for this article is retained by the author(s), with first publication rights granted to the journal.

This is an open-access article distributed under the terms and conditions of the Creative Commons Attribution license (http://creativecommons.org/licenses/by/4.0/). 